\title{
A conversation with Paul Marks
}

aul Marks is recognized as a leader in the cancer field and as a world-class scientist, clinician, and administrator. $\mathrm{He}$ served as president and CEO of Memorial Sloan-Kettering Cancer Center (MSKCC) between 1980 and 1999 after serving as the dean (1970-1973) and vice president for Medical Sciences (1973-1980) of the Columbia University College of Physicians and Surgeons (P\&S). Marks (Figure 1) led the discovery, testing, and recent approval of SAHA (suberoylanilide hydroxamic acid), the treatment for cutaneous T-cell lymphoma. SAHA and other histone deacetylase (HDAC) inhibitors are now undergoing trials for a broad array of cancers. The full interview can be seen on the JCI website, http://www.jci. org/kiosk/cgm.

JCI: Can you tell us a little bit about your path to medical school?

Marks: I was raised in a small coal town in Schuylkill County, Pennsylvania, but my mother died when I was about five and a half, so I came to live with my father's parents in Brooklyn. A teacher I had in high school, Conrad Saphier, sort of adopted me in my junior year at high school. He lost his only son, who was a Cornell Medical School graduate, in Guadalcanal and he was determined to get me to go to medical school. My grandparents weren't exactly interested, and my father wasn't around at that time. I was admitted to Columbia, which was a really cultural and life-changing experience. As we were at war in 1943, I applied for, and was accepted into, the naval officer training program. By 1945, I had completed the requirements for the degree, and the Navy had a program of sending candidates to medical school because they were concerned about having enough physicians in the service. I took the exam and got assigned to P\&S. By October 1945, the war was over and we became civilians. I became eligible for the GI Bill of Rights which helped finance my medical education.

JCI: Did you ever have a scientific bent in your studies or were you focused on being a clinician?

Marks: Actually, my interest in research started in college. My roommate in college was Josh Lederberg, a future Nobel laureate. Josh was working with Francis Ryan, who was a very prominent genetics profes- sor. Josh literally dragged me into the lab. I started working on a problem in Ryan's lab and really got hooked. I loved the idea of finding answers to questions for which we didn't immediately have an obvious answer.

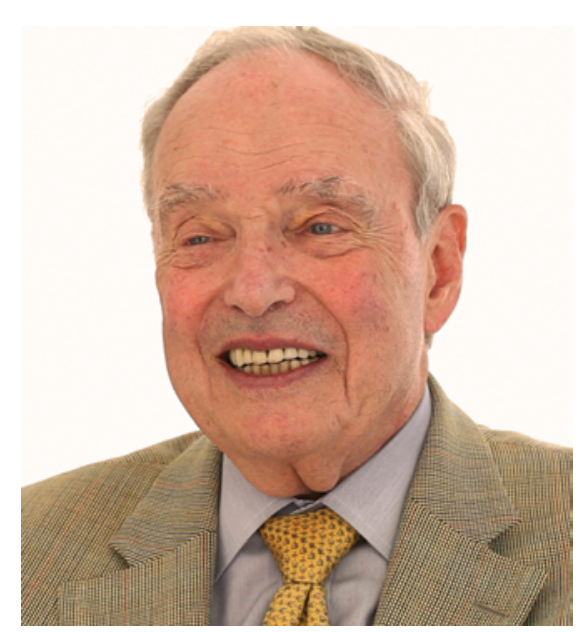

Figure 1

Paul Marks being interviewed on July 24, 2012, in New York City. Image credit: Semyon Maltsev.

On graduation from medical school, I did a two-year internship but it was interrupted in the second year because of the Korean War, and they started recruiting. I was extremely fortunate because, at that time, they were also recruiting for the new NIH's Clinical Center Research [Training] Program. But the clinical research center was still being constructed. So, I had to find something to do; it was suggested that maybe I should walk into Arthur Kornberg's lab. Somehow or other, Arthur interviewed me. He took me into the conference room and went to the blackboard, and started putting stuff on the blackboard. And he said, "Okay, this is what you're going to work on." I didn't have a clue what he was talking about. And he said, "I also want you to know that you're the first MD that I've ever had as a postdoc." I decided I'd better go to a library. But first, I looked up Kornberg. Of course, Kornberg himself was an MD.

JCI: How did you then land in Nobel Laureate Jacques Monod's lab?

Marks: When I finished at the NIH in 1955 and went back to Columbia, we worked on what was then called an alter- nate pathway of glucose metabolism: the pentose phosphate pathway. And we were working with spinach, isolating enzymes and substrates. I thought it would be interesting to see whether that pathway existed in human cells and the easiest cells to look at were red cells. One of the unexpected findings in looking at the pentose phosphate pathway in RBCs was that the first enzyme in that pathway is called glucose6-phosphate dehydrogenase (G6PD). We developed an assay for G6PD and I started looking at different individuals and I drew blood on my technician. She turned out to have a low level of G6PD. At first, I thought, "God, she doesn't know how to do the assay." So, I did it, and I still got a low level. Also at the time, I was collaborating with someone who was interested in a hemolytic anemia that she saw occasionally in a large Greek family. It turned out that they also had G6PD deficiency. As we studied them, it was clear that it was a genetic deficiency, and it was sex-linked. The issue was: how does a genetic defect cause an abnormal protein? Great things were happening - but not at Columbia - in the world of molecular biology. One of the hottest labs at the time was at the Pasteur Institute with Jacques Monod. I applied for a visiting scientist position, got a Commonwealth Fund fellowship, and off we went to Paris. We had a great experience. Monod turned out to be a great mentor. He was tough, and if he thought you were good, it was great. If he thought you weren't, you were miserable. Fortunately, he thought I was okay.

JCI: In looking at your CV of over 400 scientific articles, your research has spanned protein synthesis in globin biology to adipose tissue, to then in the latter half of your career, cancer biology. How did your trajectory lead you to the discovery and testing of SAHA?

Marks: The work on adipose tissue was fulfilling a promise I made to Alfred Gellhorn, who recruited me back to Columbia. Otherwise, I wanted to work on a human disorder that might involve a genetic defect that coded an abnormal mRNA and the role it played in transfer of information from the DNA to ribosomes and protein synthesis. I thought of thalassemia, which represented a defect in globin production - but there was no good understanding of why globin was not being made. I found 
that in $\beta$-thalassemia, the mRNA for $\beta$-globin was defective. I was working on the regulation of globin gene expression when I read a report from Charlotte Friend, who found that the solvent dimethyl sulfoxide (DMSO) induced virally transformed mouse cells to produce a red pigment. Charlotte called and asked, "What human proteins are red?” I said, "There's only one.” It was clear that she had discovered that DMSO induced these virally-transformed cells to produce hemoglobin.

One thing that struck me was that while DMSO induced globin and hemoglobin synthesis, it arrested the growth of these cancer cells without inducing their death. I decided to pursue the mechanism of the DMSO-induction of the transformed cell growth arrest. The class of compounds we worked with related to DMSO inhibited, to a greater or lesser extent, almost every transformed cell line in which they were tested. Over the years, we were able to gain a lot of insight into the mechanism of action of these compounds and discovered that SAHA inhibits histone deacetylases, specifically, HDACs $1,2,3$, and 6 , of the 11 zinc dependent HDACs in humans.

At this point, we took a human prostate cancer transplanted into a mouse and we gave it SAHA. Not only did we not kill the animals, but we also stopped the growth of the tumor; it was really a very potent and striking result. We did the necessary preclinical studies at MSKCC to get FDA approval to go into the clinic. We started clinical trials in 2001 and they were sufficiently impressive, such that the FDA let us proceed with Phase II clinical trials primarily targeted against patients with cutaneous T-cell lymphoma. It's a rare cancer, but it was at the time one that was extremely difficult to treat.

JCI: At the peak of your most exciting research findings, between ' 67 and ' 71 , you served as Editor in Chief of the JCI.

Marks: In the ' 60 s, I was very involved in the American Society for Clinical Investigation. I had a lot of buddies and looked forward to the annual meeting. The editorship of the journal came up, and I was approached by the search committee to see if I would be interested. I looked upon it as an attractive opportunity to get a broader prospective on what was going on in the research world. It was a very rewarding experience personally. I had a great group of associate editors, and we met religiously every Wednesday afternoon. It was a terrific learning experience.
JCI: Shortly after that, you were tapped to become the dean of P\&S, but you famously submitted your letter of resignation the day you started effective three years later. Why approach it that way?

Marks: I never thought I wanted to get into administration; it's strange considering what happened. I was actually chairman of the search committee to find a successor to Houston Merritt, who had resigned as dean in the wake of the general convulsions that occurred at Columbia in 1968 - the student uprisings, occupation of the university, et cetera. We came up with three outstanding candidates, but the chairman of the board of New York Presbyterian Hospital found all of our three candidates unacceptable. Without my knowledge, members of the committee suggested they invite me to be dean. I was ambivalent about it at the time but felt that the school needed leadership. So, I agreed to do it, and I thought that I could take a somewhat partial leave of absence from my research for three years but beyond that I would lose it.

JCI: Given your drive to return to research, why did you decide to take on the presidency of MSKCC?

Marks: I had, by that time, served on President Nixon's cancer panel, gotten involved both at the national level and at the school in developing cancer programs. Frankly, it was a very uphill struggle to develop what I would consider a cutting edge cancer program at Columbia Presbyterian at the time. We had very strong research in certain areas, but our clinical oncology programs were weak. In late 1979, I got a call from Laurance Rockefeller, chairman of the board at MSKCC. I thought that the challenge was extremely interesting because I felt I could both work at an institutional level, as well as the laboratory bench, in areas of cancer research and cancer care. In retrospect it turned out to be a terrific opportunity.

JCI: When you arrived there, you set about making a lot of changes. How were they received?

Marks: Well, at the level of the board, extremely well, and that was critical. They were not risk-averse - their standard was the best care we could ever provide and the best research. Programmatically, they were gung ho for doing things better and different. We had strong support to develop programs like the breast center, which was unique at the time. And the pain program was a unique program focused on pain control - you would think it would be obvious to have a program like that, in retrospect. Jimmie Holland's program in psycho-oncology was the first in the country. We developed the so-called disease management teams in the early ' 80 s, and I don't know if we were the first, but we were among the earliest to really cut across disciplines. We injected genetic counseling too - of course, my wife Joan Marks was very influential on that. It was prescient too because when she first got into training genetic counselors, cancer was not a big issue. But by the late ' 80 s and early ' 90 s, cancer was probably the biggest issue in terms of genetically at-risk individuals, and the whole understanding of the role of genetic alterations in cancer. I had strong support from the trustees to recruit excellent scientists and expand our research programs, including building a new research laboratory building.

JCI: Your son, Andrew Marks, has followed in some of your footsteps - becoming an MD, filling a professorship at Columbia, and acting as editor in chief of the JCI. But, you have dissuaded him from taking on an administrative or leadership role. Why?

Marks: Well, I'm prejudiced, but I think he's an extremely talented scientist and has been extremely productive. And there's no question that I feel that I made compromises in my research. I don't know what I could've accomplished that I didn't, but I sort of feel that I could have accomplished a lot more if I had just focused on the research. Bringing SAHA to the clinic was something that I was able to do after I stepped down as president. And, I feel that Andy has terrific research and I think his contributions have been very, very important. For him to take on a major administrative role right now, which he has been tempted to do from time to time, would perhaps compromise his focus on research. All I can do is advise him, but I'm not going manhandle him on what he wants to do.

JCI: If you were to do something other than science or medicine, what do you think it would have been?

Marks: I would be a curator in a good museum. I'm very interested in art as my daughter and my younger son are both involved in the art world. From the time when they were young, we dragged them through every museum in every country we visited. So, art has always been a passion, and still is.

\section{Ushma S. Neill}

